\title{
A Review on the Application of Multiphase Twin Screw Pump as a Downhole Wet Gas Compressor to Improve Gas Wells Recovery Factor
}

\author{
Sharul Sham Dol \\ Department of Mechanical \\ Engineering \\ Abu Dhabi University \\ Abu Dhabi, P.O. Box 59911 \\ UNITED ARAB \\ EMIRATES \\ sharulshambin.dol@adu.ac.ae
}

\author{
Niraj Baxi \\ GE Power Systems Malaysia \\ Sdn. Bhd. \\ Wilayah Persekutuan \\ 50088 Kuala Lumpur \\ MALAYSIA \\ nirajdbaxi@gmail.com
}

\author{
Mior Azman Meor Said \\ Department of Mechanical \\ Engineering, Universiti \\ Teknologi PETRONAS \\ 32610 Seri Iskandar, Perak \\ MALAYSIA \\ miorazman@utp.edu.my
}

Received: March 23, 2021. Revised: September 2, 2021. Accepted: October 11, 2021. Published: October 14, 2021.

\begin{abstract}
By introducing a multiphase twin screw pump as an artificial lifting device inside the well tubing (downhole) for wet gas compression application; i.e. gas volume fraction (GVF) higher than $95 \%$, the unproductive or commercially unattractive gas wells can be revived and made commercially productive once again. Above strategy provides energy industry with an invaluable option to significantly reduce greenhouse gas emissions by reviving gas production from already existing infrastructure thereby reducing new exploratory and development efforts. At the same time above strategy enables energy industry to meet society's demand for affordable energy throughout the critical energy transition from predominantly fossil fuels based resources to hybrid energy system of renewables and gas. This paper summarizes the research activities related to the applications involving multiphase twin screw pump for gas volume fraction (GVF) higher than 95\% and outlines the opportunity that this new frontier of multiphase fluid research provides. By developing an understanding and quantifying the factors that influence volumetric efficiency of the multiphase twin screw pump, the novel concept of productivity improvement by a downhole wet gas compression using above technology can be made practicable and commercially more attractive than other production improvement strategies available
\end{abstract}

today. Review and evaluation of the results of mathematical and experimental models for multiphase twin screw pump for applications with GVF of more than $95 \%$ has provided valuable insights in to multiphase physics in the gap leakage domains of pump and this increases confidence that novel theoretical concept of downhole wet gas compression using multiphase twin screw pump that is described in this paper, is practically achievable through further research and improvements.

Key-Words: - Twin screw pump; Gap leakage; Gas volume fraction; Downhole; Multiphase; Performance curve; Pressure drop; Volumetric efficiency; Wet gas

\begin{tabular}{ll}
\multicolumn{2}{c}{ Nomenclature } \\
$\begin{array}{l}\eta_{\mathrm{v}} \\
\text { Volumetric } \\
\text { efficiency }\end{array}$ & $\begin{array}{l}\text { GVF Golume } \\
\text { vaction } \\
V_{\text {act Actual }}\end{array}$ \\
displaced & ESP \\
volume & Electrical \\
submersible \\
$V_{\text {theo }}$ & pump \\
Theore & $\mathrm{CO}_{2}$ \\
tical displaced & Carbon \\
volume & dioxide \\
$C F D$ & $H 2 S$ \\
Computational & Hydrogen \\
fluid dynamics & sulfide
\end{tabular}




\section{INTRODUCTION}

The geopolitical scene and socio-economic factors are significantly influencing the ongoing evolution in exploration and production of hydrocarbon reserves. The nature and science of exploration and production has evolved over the last couple of decades. Due to limited recovery factor and pressure depletion of existing gas wells, investments made in existing reserves are becoming unprofitable much early and are unable to sustain long term market demand. There is an increasing market push to improve financial efficiency by reducing unit development cost and even bigger focus on reduction of carbon emissions from production facilities. At the time of writing this paper the world is grappling with sudden structural shift and transformation in global energy and commodities demand-supply equilibrium. Renewed vigor and determination of governments towards harmful effects on climate due to man-made greenhouse gas emissions was demonstrated by signing of the United Nations Framework Convention on Climate Change (UNFCCC) agreement in Paris in 2015 by the Intergovernmental Panel for Climate Change; whose priority objective amongst many other sustainable development goals for planet, is to aggressively pursue reduction in carbon emissions and limit the widespread harmful effects on ecosystem by holding earth's temperature rise to 2 deg. $\mathrm{C}$ above pre-industrial levels.

For the economy to rapidly adapt and energy industry to transition in to 'low carbon' and thereafter to 'carbon-neutral' environment, it is uneconomical, unethical and inefficient if industry continues to adopt business strategy in which on one hand significant quantity of hydrocarbon gas is left behind in existing gas wells due to poor recovery factors and our inability to extract further; and on other hand we keep exploring and developing new gas fields, which again are not being fully utilized. In above context there is a remarkable dichotomy that is beginning to evolve in the energy industry. On one hand the crude oil producers are beginning to review their current strategy and are more focused on improving recovery factors instead of aggressive pursuit of new fossil fuel reserves, as evident in [1]. The gas producers on the other hand have not been as effective in emulating the strategy adopted by crude oil producers due to dearth of proven, efficient and cost effective technologies focused on improving recovery factor.

To address plethora of above technical, environmental and business challenges; lot of research and development efforts have been ongoing on variety of sub-sea / sub-surface and downhole technologies. One such area where extensive research has been performed is the sub-sea multiphase pumping technology. This review paper summarizes the research that has been conducted on multiphase twin screw pumping technology and highlights the shortcomings in performance of multiphase twin screw pump technology when applied to fluids with gas volume fraction (GVF) above $95 \%$; i.e. wet gas compression. The paper also summarizes unique advantage that positive displacement principle of multiphase twin screw pump provides for fluid applications with GVF above $95 \%$ than helico-axial or centrifugal pump, which are based on rotor-dynamic multiphase pumping technology.

The objective of paper is to showcase a novel concept of multiphase twin screw pump technology as a downhole wet gas compressor and provide a subtle understanding to the readers that the proposed novel concept has all the attributes to be a 'silver bullet' solution to maneuver the process of delicate transition from 'fossil fuel' based economy to an economy that is based on hybrid energy system consisting of renewables and fossil fuels.

A. State-of-the-Art in Multiphase Pumping Technology Conventional multiphase pumping systems for subsea and subsurface applications in oil and gas industry have been around for a long time and have undergone different phases of evolution in order to meet ever growing demand for more challenging applications and operating conditions, as demonstrated in [2-5]. The graphical representation in the Figure 1 depicts the current state-of-the-art in the field of sub-sea pumping. It is observed that choices rapidly reduce with increasing \% GVF and required differential pressure. The circled area in the Figure 1 below is the region of focus of this review paper.

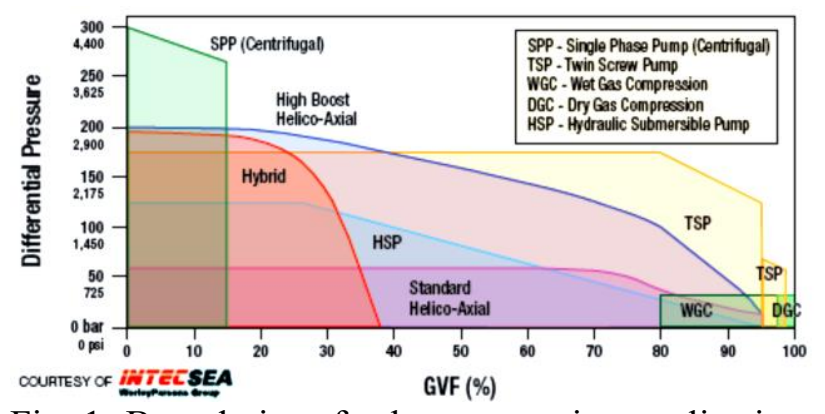

Fig. 1: Boundaries of sub-sea pumping applications (from [4])

Evolution process of design of multiphase pumps, selection of hydraulics and refinement in its component design have happened up until now 
based on traditional principles and understanding of component failure modes, examples of which are represented in [6-7]. Novel developments published in [8-9], the electric submersible pump (ESP) and its variants called as hybrid booster pumps, whose initial stages consist of gas tolerant impeller design; are able to handle fluids up to $20 \%$ GVF. However, due to increasing gas content in well fluids as the field reaches its maturity, the ESP technology will not be able to find a suitable place in exploration and production strategies of hydrocarbon reserves. Above limitations were addressed by a 'helicoaxial' pump technology with some radically modified pump hardware. A pictorial representation of typical helico-axial pump is shown in the Figure 2. It consists of fully axial flow impellers that are separated by axial diffuser stages, which can operate on well fluids up to $65-70 \%$ GVF.

As the applications begins to approach GVF of above $80 \%$, clear demarcation between a multiphase pump and a multiphase compressor begins to diminish and this situation led to emergence of two promising frontiers in the multiphase compression technology. One of the promising frontiers is the multiphase twin screw pumping technology that is a successful extension of proven capabilities of twin screw pumps operating with Newtonian and nonNewtonian fluid applications. A pictorial representation of typical multiphase twin screw pump is shown in the Figure 3.

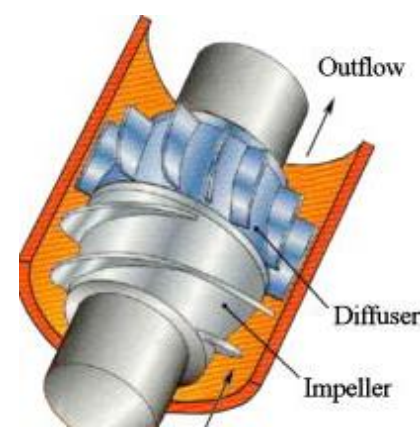

Fig. 2: Typical Helico-Axial Multiphase Pump [10]

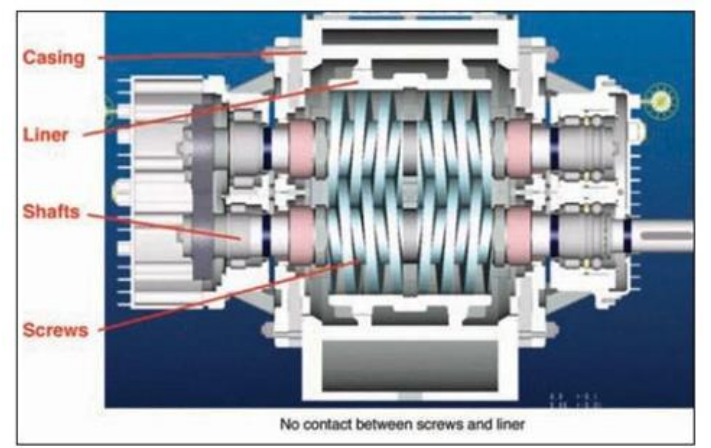

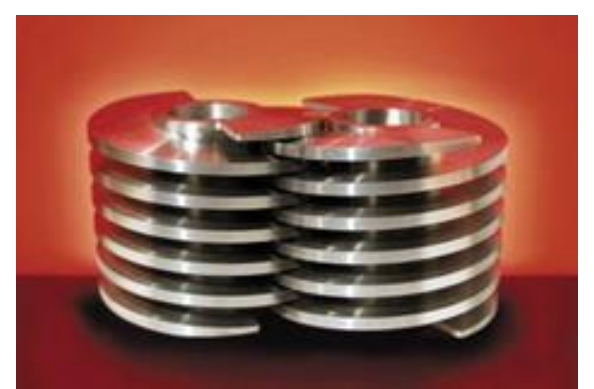

Fig. 3: Typical Multiphase Twin Screw Pump (top); typical screw elements (bottom)

The multiphase twin screw pump technology has proved its capability to operate until $95 \% \mathrm{GVF}$, but has not been sustainably proven beyond $95 \%$ GVF. Supported by the research works of [6 \& 11], it is worthwhile to conclude that the multiphase twin screw pump is one of the only two proven technologies that is considered to be best suited for sub-sea multiphase pumping applications. The only other technology is the helico-axial multiphase pump, which is based on rotor-dynamic (centrifugal) principle, which poses design and operating limitations for applications above 95\% GVF. Helico-axial multiphase pump is outside the scope of this review paper.

\section{NOVEL APPLICATION OF MULTIPHASE PUMPING TECHNOLOGY}

As demonstrated in [12-16], there are efforts being made to focus on application of multiphase pumping to increase productivity and to improve recovery factors of existing hydrocarbon liquid reservoirs. Production gains in the range of 30 to $40 \%$; from what is commonly known as 'marginal oil fields', have been realized due to renewed scientific efforts. While the current multiphase pumping technology has been focusing on 'marginal oil fields'; not much focus has been provided on the research of multiphase artificial lift technology for 'marginal gas fields', which is an application where GVF would be above $95 \%$ all the time.

Through novel approach of miniaturization of existing multiphase screw pump technology and adapting it to suit downhole gas application provides an opportunity to develop an artificial lift technology for multiphase gas application, which does not exist as of today. The novel approach would complement the pace of technological improvements that are happening in field of gas reservoir characterization. The Figure 4 shows conceptual sketch of downhole gas compressor installation and its integration with production system. Miniaturized multiphase twin screw pump 
and its integration with downhole production system would provide an efficient, economical and sustainable solution for reviving 'marginal gas fields' and commercially unattractive gas wells.

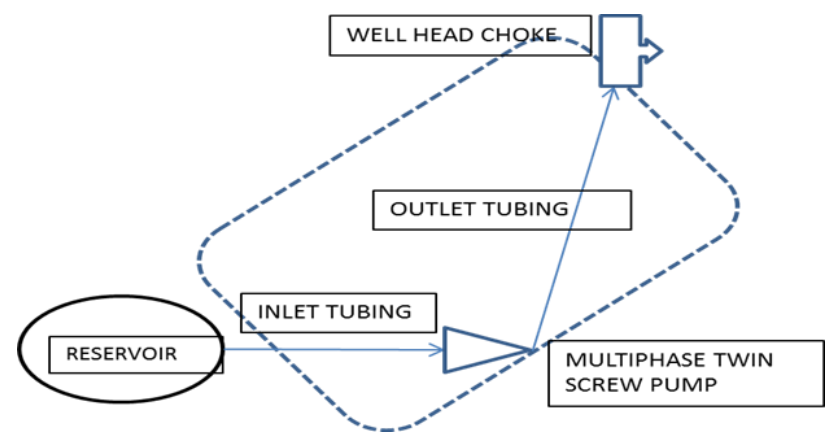

Fig. 4: Conceptual sketch of downhole compressor and its integration with production

\section{A. Miniaturization for Productivity and Efficiency Improvement}

Basic concept of downhole gas compressor and its benefits are reported in patent US 7401655 B2, which is a premonition that the industry is serious about studying the feasibility of novel concept of downhole gas compression. Significant advantage that a downhole gas compression provides over a subsea compression or gas compression on platform; apart from the fact that it provides higher recovery factor than currently available sub-sea compression technologies, is that it has highest overall process efficiency than all the other production processes as shown in $\left[\begin{array}{lll}17 & \& & 18\end{array}\right]$. Introduction of an artificial lift device in the form of high speed axial compressor inside the depleting gas well is presented in [15 \& 17]. Both the studies demonstrated dramatic productivity improvements. Tullio et al. [15] studies however only dealt with water vapor condensation from gas stream and studies by [17] only dealt with single phase, dry natural gas, neither of which are considered to be realistic representation of actual multiphase fluid conditions inside a typical gas well. For an artificial lift device inside the downhole gas application, all fluid dynamic and thermodynamic process interactions taking place inside an integrated production system can be accounted only by considering the fluid to be multiphase hydrocarbon fluid.

\section{B. Multiphase Twin Screw Technology for Downhole Wet Gas Compression}

Multiphase twin screw pump brings unique advantages to the miniaturization concept of a downhole wet gas compressor application. The merits that the virtue of a positive displacement principle imparts to the concept are as follows:
1) The twin screw design is more efficient, as energy is imparted gradually with every small degree of rotation of the screw elements. The compression process is able to maintain quasi-equilibrium state and is therefore relatively more efficient. This topic carries more scientific relevance for a multiphase fluid compression with different droplet sizes and droplet concentrations.

2) Reduced fluid friction losses due to very low rate of shear, which again makes the compression process more efficient.

3) Flow path design is relatively insensitive to molecular weight variations and therefore also insensitive to compression process constraints set by speed of sound in gas. This makes twin screw type design relatively compact and more versatile, in particular for a gas application with significant $\mathrm{CO}_{2}$ and $\mathrm{H} 2 \mathrm{~S}$ content, which tends to increase the molecular weight.

4) The design is sturdier and more reliable for a wet gas compression application, where large variations in GVF can cause variety of multiphase flow regimes; e.g. slug, dispersed, annular flows, which give rise to constantly changing liquid droplet sizes and droplet velocity in the production system.

5) Liquid 'unloading' inside the well tubing or pipeline increases differential pressure in well tubing and/or pipeline once critical velocity threshold is reached; a behavior which is the main reason for reduction in production rates and wells to become commercially unproductive. Characteristic of positive displacement principle is that it provides almost constant flow across the range of differential pressures. The linear behavior is a significant advantage when it comes to a down hole and a sub-sea process control application. In contrast. an artificial lift technology that is based on rotordynamic principle possess non-linear 'drooping' characteristic like that of centrifugal pump or compressor, which would set serious constraints on management of critical velocity that have to be dealt with complex process and production control strategies. 
III. GaP LEAKAGES AND Volumetric EFFiCIENCY Typical volumetric efficiency of a multiphase twin screw pump is given as:

$\eta_{v}=\frac{V_{\text {act }}}{V_{\text {theo }}}$

The author performed extensive review of analytical and experimental performance data of the multiphase twin screw pumps published by other researchers over a decade. The published volumetric efficiency performance data sets of various researchers, for variety of different GVF, differential pressure, inlet pressure and speed, were regrouped in to one single set of raw data and analyzed to understand specific behavior of multiphase twin screw pump in wet gas compression region; i.e. GVF above $95 \%$.

The figure 5 and 6 below shows patterns of performance variations in the neighborhood of $95 \%$ GVF and $100 \%$ GVF. It is evident from the two patterns that there is significant step change in volumetric efficiency between the data set representing neighborhood of $95 \% \mathrm{GVF}$ and the data set representing neighborhood of $100 \%$ GVF. At and around 95\% GVF the spread of the volumetric efficiency is in the range of $90 \%$ and $50 \%$, while around $100 \%$ GVF there is sharp decline in the volumetric efficiency and spread it is bound between $85 \%$ and $35 \%$.

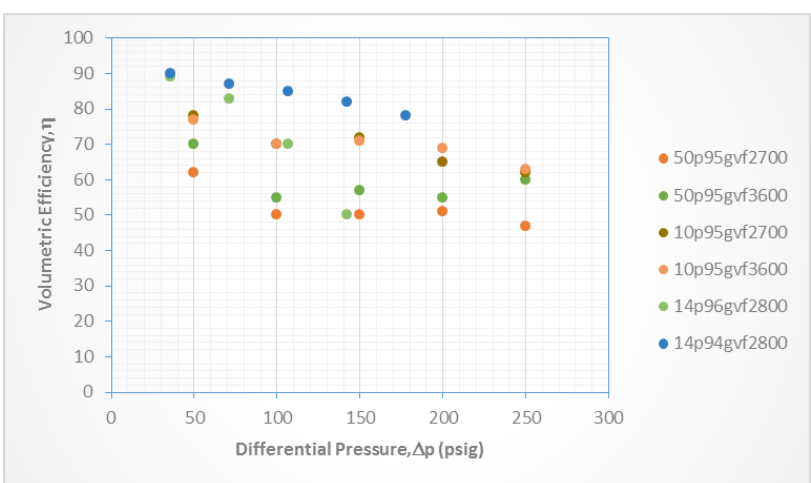

Fig. 5: Multiphase Twin Screw Pump performance in the neighborhood of $95 \%$ GVF

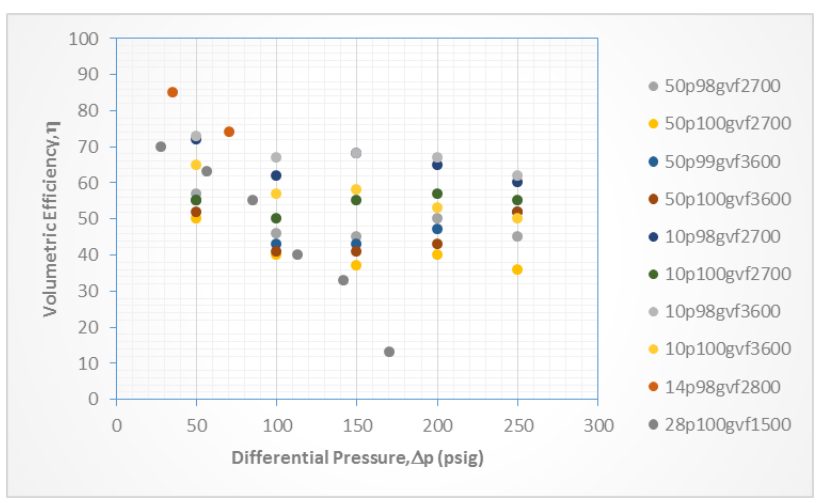

Fig. 6: Multiphase Twin Screw Pump performance in the neighborhood of $100 \% \mathrm{GVF}$

By comparing above range of volumetric efficiency at $95 \%$ GVF and $100 \%$ GVF; i.e. $90-50 \%$ and $85 \%-35 \%$ respectively; it reconfirms that the idea of downhole wet gas compression using multiphase twin screw pump is practicable and meaningful. It also confirms that there is a significant opportunity to extend the quality of higher volumetric efficiency demonstrated by a multiphase pump for 95\% GVF to operating conditions around $100 \%$ GVF. For example, a meager $5-10 \%$ increase in volumetric efficiency for operating conditions above $95 \%$ GVF will translate in to significant improvement in recovery factor of a gas well.

Figure 7 represents typical gap leakages in multiphase twin screw pump, which are the major areas where variety of research has been performed on characterization of the gap leakages with significant level of success. However, the research outcomes are valid only for specific operating conditions and flow characteristics.

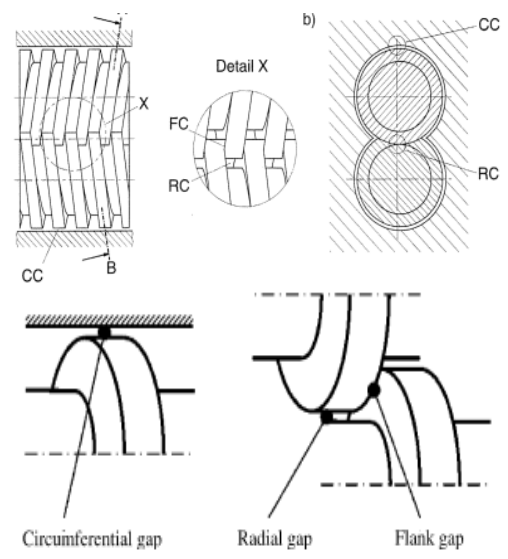

Fig. 7: Gap leakages; CC-Circumferential, RCRadial, FC-Flank, (top) [19]; (bottom) [20]

As evident in [11, 19-22], the gap leakages contribute to majority of mass and energy loss that is experienced during the compression process and therefore for last several decades researchers have attempted to estimate leakages as accurately as possible and even as on date best practical approach to determine gap leakage remains elusive.

As observed in [23 \& 24], while approaching threshold of $85 \%$ GVF, fluid in the perimeter gap area becomes genuine multiphase liquid-bubble mixture whose density is function of bubble distribution and bubble size, as reported in [25].

Previous researchers [26-28] studied and reported results of transient effects of slug flows; i.e. 
GVF of $98 \%$ to $100 \%$ for a limited time period. The temperature increased within short period of time due to heat generation by the multiphase compression process and eventually caused rotor deformation followed by rapid decline in pumping efficiency, ultimately leading to loss of pumping action.

For reliable and efficient operation, it is essential to abate the temperature rise inside the pump by evacuation of heat of compression. Couple of alternatives of how this can be achieved is either by continuous injection of $5-6 \%$ of liquid or increasing the volumetric efficiency or combination of the two.

It is estimated in [19] that of the total leakage flow, the perimeter leakage flow accounts for $80 \%$ of the total leakage flow, while remaining is contributed by the radial and the flank clearances. It is reported in $[11 \&$ \& 22] that the leakage flow through the flank gap does not significantly contribute to the total leakage and therefore it does not affect the performance of the pump. The performance evaluation made in [29], with and without the flank gap leakage confirmed that the leakage through the flank gap does significantly affect the performance in high GVF cases, which is in complete contrast to observations made in $[11,19$ and 22]

Typical graph in the Figure 8 represents the role of flank gap leakage under high GVF conditions, which is quantified through experimental investigations by comparing the calculated pressure increase profile against the actual pressure rise in [29]. The experiment also measured and recorded the volumetric efficiency and the temperature rise; in a steady state boundary conditions and in an unsteady state boundary condition scenario of the slug flow at the pump inlet.

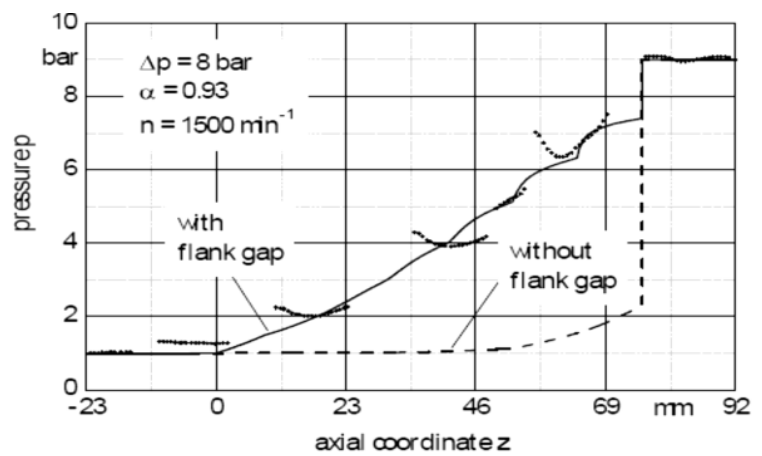

Fig. 8: Actual pressure rise with flank leakage and calculated pressure rise without flank leakage [29]

\section{A. Limitations in Gap Leakage Prediction Models}

The computational models based on the analytical equations in [19, 22, 23 and 27] do not explicitly confirm reliability of model to predict performance of a multiphase twin screw pumps under variety of operating conditions in the region of wet gas compression; i.e. GVF more than $95 \%$. There is also very little literature regarding experimental validation of the mathematical models in the region of wet gas compression. Patil [25] research studied performance of twin screw compressor with airwater mixture fluid properties using computational fluid dynamic (CFD) and experimental techniques for conditions closest to wet gas compression.

The areas of improvement observed in published literatures on the analytical gap leakage models can be summarized as follows:

1) From evaluation of most popular analytical models referred to in above section, it is evident that researchers use approximations in treating the gap leakage either as a single phase incompressible liquid or as a homogenous two phase fluid. Approximation significantly simplifies the gap leakage problem and validity of the analytical models for wet gas compression operating regime becomes questionable.

2) In cases where the numerical techniques have been implemented, the models are in 2D domains for economical computing. Due to this deliberate simplification, valuable information regarding flow characteristics, combined effects of pressure driven and shear force driven gap leakage; and phase changes occurring in the perimeter, the radial and the flank gap leakage areas, remain unaccounted.

3) Combination of factors like phase change in hydrocarbon mixtures, solubility of gas in hydrocarbon liquid phase and degassing, liquid-bubble mixture, bubble size, bubble distribution cause unsteady fluid velocities and fluid properties are discussed in [23 and 30-31]. Effects of above factors become even more pronounced at higher GVF due to increased compressibility and density variations [32-36]. Due to large number of properties with spatial and temporal variations that are involved in a property transport equation, it is impractical to analytically model every aspect of above phenomenon without compromising the quality of results by making assumptions and simplifications. Above argument is also supported in [25]. 
4) As per the results of study presented in [37] it is demonstrated that accuracy of friction pressure drop in the microchannel with two phase flow depends on ability to accurately represent the actual flow pattern of two phase flow model. The gap leakage model in [19] is based on homogenous two phase flow model, while in $\left[\begin{array}{lll}11 & \& & 28\end{array}\right]$ the gap leakage model is based on separated flow model, both of which as per [37] lead to relatively less accurate friction pressure drop estimates.

5) Computer models described in $[24,25,30$, 38 and 39] have not been validated using hydrocarbon, oil, water mixtures. Experimental validation of the models so far has been performed either with water-air, water-air-paraffin oil mixtures, and / or paraffin oil-carbon dioxide mixture. which again leads to simplification of intricate multiphase physics.

\section{B. Physics of Multiphase Flow Related to Gap Leakage}

The review and evaluation of mathematical models used to study the multiphase twin screw pump behavior, consider the gap leakages broadly in to following two types of flow characteristics:

1) A homogenous two phase fluid for the perimeter gap, the radial gap and the flank gap leakage.

2) A single phase incompressible viscous liquid for the perimeter gap leakage and a homogenous two phase fluid for the radial gap and the flank gap leakage.

Above hypothesis is verified in [25 \& 39] through direct flow visualization using a high speed camera and confirmed visible variations in quality of flow characteristics, if not represented correctly in the mathematical model these can significantly influence the gap leakage flows and ultimately performance predictions.

A typical flow characteristics in the perimeter gaps of the screw element from the excellent research work of [20] is shown in the Fig. 9. The figures show interesting evolution of flow characteristics in the perimeter gaps when a specific model of multiphase twin screw pump was operated in the range of GVF from $90 \%$ to $98 \%$.

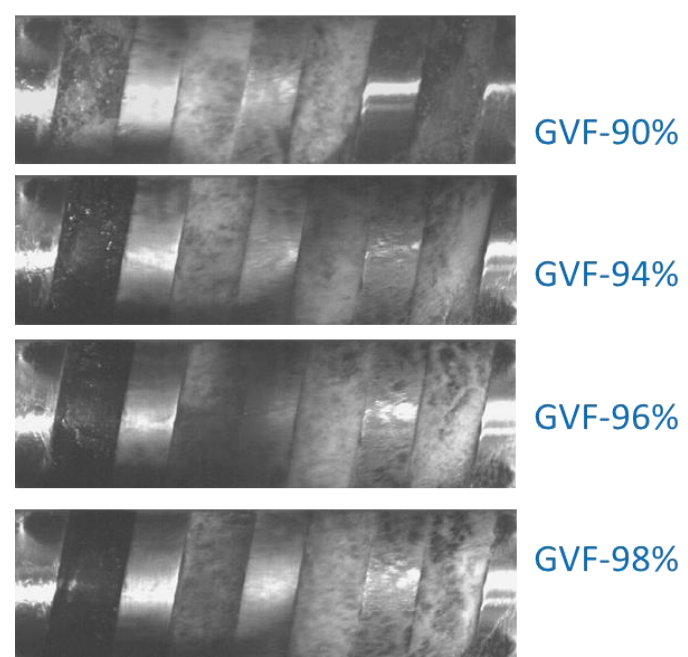

Fig. 9: Typical flow characteristics in perimeter gap [20]

Collection of data sets on friction pressure drop in two phase flow represented in [40] provides a new universal friction pressure drop prediction correlation for various sizes of micro / mini channels. As reported in [40-42] only few correlations for two phase pressure drop have fair prediction capability. Two phase gas-liquid flow patterns and friction pressure drop in microchannel (100-200 microns) show very different behavior than the flows through macro channels, as reported in [37]. Comparison between experimental results of two phase friction pressure drop and predicted values of three different flow models; i.e. separated flow model, homogenous flow model and flow pattern based phenomenological models (bubble, ring, slug and annular) provided in [37] concludes that two phase friction pressure drop in microchannel can be predicted more accurately by flow pattern based phenomenological models than by homogenous flow model or separated flow model. The author compared above fundamental research in multiphase physics in microchannel with the mathematical models and it is observed that in [19] the gap leakage model is based on homogenous two phase flow model [11 \& 25] the gap leakage model is based on separated flow model.

It is reasonable to conclude that none of the leakage flow prediction models for a multiphase twin screw pump have been based on flow pattern based phenomenological model, which as mentioned above is one of the more accurate methods of predicting friction pressure drop than the other methods. 


\section{RECOMMENDATION AND CONCLUSION}

Further research in improving the volumetric efficiency of a multiphase twin screw pump offers a huge opportunity for a downhole wet gas compression and would contribute following value to existing scientific knowledge:

1) The numerical techniques provide fluid dynamic and thermodynamic modeling framework for multiphase twin screw pump applications dealing with high GVF; i.e. wet gas compression. Adopting a numerical modeling procedure would provide flexibility to virtually experiment with the model and test variety of complex phenomenon economically [43], minimize deliberate simplifications of the problem and would reduce time for developing solutions for volumetric efficiency improvement. The framework would then be used for performing further research by addressing the specific shortcomings of various published mathematical models discussed in the review paper and refine the gap leakage characterization prior to studying solutions to increase volumetric efficiency for the cases in the neighborhood of $100 \%$ GVF.

2) Continuous fluid and thermodynamic interactions between a multiphase twin screw pump and well tubing would induce transient GVF, pressure and temperature drops in well tubing and therefore variable fluid critical velocity. Understanding of above behavior is essential to decide the depth at which the multiphase screw pump should be installed and develop pump control strategies for efficient and reliable production. Careful selection of the position of a wet gas compression device in the tubing will enable to maximize utilization of naturally available driving energy of reservoir and optimize the size of the pumping device only to meet additional driving energy necessary to maintain velocity in the tubing above critical velocity of 'liquid drop out'. Understanding of above behavior, in general, is also of immense value to the research community that engages in modeling a multiphase flow regime in well tubing and pursues solutions to improve well productivity.

\section{REFERENCES}

[1] Goswami S. (2015). Multiphase pumping to enhance oil recovery. International Journal of Engineering Trends and Technology, V21(2), 67-71 (March 2015).

[2] Kassem, O. M., A. Q. Abdullah, S. S. Dol, M. S. Gadala, and M. S. Aris. "CFD Analysis on the Single-Phase Flow Electrical Submersible Pump Performance Curve." PLATFORM-A Journal of Engineering 4, no. 4 (2020).

[3] Salman Shahid, Abdul Qader Hasan, Sharul Sham Dol, Mohamed S. Gadala, Mohd. Shiraz Aris, "Effects of Near-Wall Vortices on Wall Shear Stress in a Centrifugal Pump Impeller", WSEAS TRANSACTIONS ON FLUID MECHANICS, 16, pp. 37-47, 2021.

[4] Salman Shahid, Sharul Sham Dol, Abdul Qader Hasan, Omar Mustafa Kassem, Mohamed S. Gadala, Mohd. Shiraz Aris, "A Review on Electrical Submersible Pump Head Losses and Methods to Analyze TwoPhase Performance Curve", WSEAS TRANSACTIONS ON FLUID MECHANICS, 16, pp. 14-31, 2021.

[5] Salman Shahid, Abdul Qader Hasan, Sharul Sham Dol, Mohamed S. Gadala, Mohd. Shiraz Aris, EFFECTS OF GAS VOLUME FRACTIONS ON ELECTRICAL SUBMERSIBLE PUMP PERFORMANCE UNDER TWO-PHASE FLOW. Platform : A Journal of Engineering, [S.1.], v. 5, n. 2, p. 2-9, June 2021.

[6] Bibet P; Quoix B. \& Grimstad H. (2009). Hybrid pump - A new type of pump for The Pazflor deep sea project. In 25th International Pump Users Symposium, Houston (February 23-26, 2009).

[7] Cooper P; Schiavello B; de Marolles C; de Salis J; Prang A. J \& Broussard D. H. (1996) Tutorial on multiphase gas - liquid pumping. In 13th International Pump Users Symposium, Houston. (March 5-7, 1996).

[8] Abelsson C; Busland $\mathrm{H}$; Henden R; Homstvedt G; Olderheim T. \& Westborg T. (2011). Development and testing of hybrid boosting pump. Offshore Technology Conference, Houston, (2-5 May 2011).

[9] Scott, S. L. (2003). Multiphase pumping addresses a wide range of operating problems. Special Report, Oil \& Gas Journal, 101(37).

[10] Cao S; Peng G. \& Yu Z. (2004). Hydrodynamic Design of Rotodynamic Pump Impeller for Multiphase Pumping by 
Combined Approach of Inverse Design and CFD Analysis, Journal of Fluids Engineering 127(2), 330-338 (October 01, 2004).

[11] Feng C; Yueyuan P; Ziwen X. \& Pengcheng S. (2001). Thermodynamic performance simulation of a twin-screw multiphase pump. Proceedings of the Institution of Mechanical Engineers, Part E: Journal of Process Mechanical Engineering, 215(2), 157-163.

[12] Al-Anazi R. S; Shaleh M. A; Al-Hasan E. \& Al- Buali M. H. (2013). Field experience with first twin screw multiphase pump in Saudi Arabia oilfield. International Petroleum Technology Conference, Beijing (26-28 March 2013).

[13] MacNeil D; Dass P. (2012). Replacing ESP and gas lift with electric submersible twin screw pump. Society of Petroleum Engineers Artificial Lift Conference and Exhibition, Manama (November 27-28, 2012).

[14] Ohanyere I.J. \& Abili N. (2015). Reassessment of subsea processing technology to maximize recovery on offshore marginal field development. Offshore Technology Conference, Houston, (May 4-7, 2015).

[15] Tullio M.T. Di; Fornasari S; Ravaglia D; Bernatt N \& Liley J.E.N. (2009). Downhole Gas Compression: world's first installation of new artificial gas lifting system for gas wells. EAGE Annual Conference and Exhibition, Amsterdam, (June 8-11, 2009).

[16] Dol, S. S., Chan, M. S., Wong, S. F., \& Lim, J. S. (2016). Experimental Study on the Effects of Water-in-Oil Emulsions to the Pressure Drop in Pipeline Flow. International Journal of Chemical and Molecular Engineering, 10, 1528-1535.

[17] Hossain M. \& bin Mohd. Ismail M. D. (2013). Potential application of downhole gas compressor to improve productivity of gas reservoir. International Petroleum Technology Conference, Beijing (March 26-28, 2013).

[18] Muller-Link D; Brandt J.U; Reichwage M. \& Schroder G. (2002). Wet gas compression - A logical step to follow multiphase pumping. 10th Abu Dhabi International Petroleum Exhibition and Conference (October 13-16, 2002).

[19] Vetter G; Wirth W; Korner H \& Pregler S. (2000). Multi-phase pumping with twin screw pumps - Understand and model hydrodynamics and hydro-abrasive wear. 17th International Pump Users Symposium, Houston (2000).

[20] Räbiger K; Maksoud T.M.A; Ward J. \& Hausmann G. (2008). Theoretical and experimental analysis of a multiphase screw pump handling gas-liquid mixtures with very high gas volume fractions. Experimental Thermal and Fluid Science 32(8), 1694-1701.

[21] Neumann W. (1991). Efficient multiphase pump station for onshore application and prospects of offshore application. 8th International Pump Users Symposium, Houston (March 5-7, 1991).

[22] Prang A. J. \& Cooper P. (2004). Enhanced multiphase flow predictions in twin screw pumps. 21st International Pump Users Symposium, Houston (2004).

[23] Nakashima C. Y; de Oliveira Jr. S. \& Caetano E.F. (2004) Thermo-hydraulic model of twin screw multiphase pump Proceedings of International Mechanical Engineering Congress, California (November 13-20, 2004).

[24] Rausch T; Vauth T; Reichwage M. \& Mewes D. (2005). Experimental and theoretical investigations of multiphase twin screw pumps for new offshore applications. 15th International Offshore and Polar Engineering Conference, Seoul (June 19-24, 2005).

[25] Patil A. (2013). Performance evaluation and CFD simulation of multiphase twin-screw pumps, $\mathrm{PhD}$ Thesis, Texas A\&M University (2013).

[26] Gao T; Yang D; Cao F. \& Jiao J. (2011). Temperature and thermodynamic deformation analysis of the rotors on a twin screw multiphase pump with high gas volume fractions. In Journal of Zhejiang University-Science A (Applied Physics \& Engineering), 12(9), 720-730.

[27] Nakashima C. Y; de Oliveira Jr. S. \& Caetano E.F. (2006). Heat transfer in a twin-screw multiphase pump: Thermal modeling and one application in the petroleum industry. Energy 31 (2006), 3415-3425.

[28] Xu Jian; (2008). Modelling of Wet Gas Compression in Twin-Screw Multiphase Pump, PhD Thesis, Texas A\&M University, 2008. 
[29] Mewes D; Aleksieva G; Scharf A. \& Luke A. (2008). Modelling twin-screw multiphase pumps - A realistic approach to determine the entire performance behavior, 2nd International EMBT conference, Hannover (April 16-18, 2008).

[30] Groth T; Reichwage M; Mewes D. \& Luke A. (2009). Effects of dissolving and degassing phenomena on multiphase oil and gas boosting, 14th International Conference on Multiphase Production Technology, Cannes (June 17-19, 2009).

[31] Hatesuer F; Reichwage M; Lewerenz J. \& Luke A. (2011). Pressure pulsations in twinscrew multiphase pumps conveying oil and air. In 21st International Offshore and Polar Engineering Conference, Hawaii (June 1924, 2011).

[32] Wong, Siew Fan, Ming Chiat Law, Yudi Samyudia, and Sharul Sham Dol. "Rheology study of water-in-crude oil emulsions." Chemical Engineering Transactions 45 (2015): 1411-1416.

[33] Siew Fan Wong, Sharul Sham Dol, "Turbulence Characteristics Study of the Emulsified Flow", WSEAS TRANSACTIONS ON HEAT AND MASS TRANSFER, 14, pp. 45-50, 2019.

[34] Dol, Sharul Sham, S. F. Wong, S. K. Wee, and J. S. Lim. "Experimental Study on the Effects of Water-in-oil Emulsions to Wall Shear Stress in the Pipeline Flow." Journal of Applied Fluid Mechanics 11, no. 5 (2018): 1309-1319.

[35] S.S. Dol, L.J. Sen. "The effect of dissipation energy on pressure drop in flow-induced oil-water emulsions pipeline", WSEAS Transactions on Environment and Development, 14, pp. 182-189, 2018.

[36] Sharul Sham Dol, Lim Jit Sen. "The Effect of Flow-Induced Oil-Water Emulsions on Pressure Drop". International Journal of Theoretical and Applied Mechanics, 2, pp. 73-78, 2017.

[37] Sur A. \& Liu D. (2011). Adiabatic air-water two-phase flow in circular micro-channels, International Journal of Heat and Mass Transfer, 53 (2012), 18-34.

[38] Aleksieva G; Rausch T; Vauth T; Scharf A; Reichwage M. \& Mewes D. (2006). Experimental investigation and calculation of multiphase screw pumps of conventional and new improved design. In 16th International Offshore and Polar
Engineering Conference, San Francisco. (May 28-June 2, 2006).

[39] Hatesuer F; Groth T; Reichwage M; Mewes D. \& Luke A. (2010). Investigation of sorption phenomena in multiphase conveying processes. In 7th North American Conference on Multiphase Technology, Banff (June 2-4, 2010).

[40] Kim S; Mudawar I. (2012). Universal approach to predicting two-phase frictional pressure drop for adiabatic and condensing mini/micro-channel flows. International Journal of Heat and Mass Transfer, 55 (1112), 3246-3261.

[41] Fan, Wong Siew, and Sharul Sham Dol. "Application of Ultrasonic Velocity Profiler (UVP) in the Crude Oil Emulsion Pipeline Flow." Advanced Aspects of Engineering Research Vol. 15 (2021): 112-124.

[42] Mustafa Ozsipahi, Sertac Cadirci, Hasan Gunes, Husnu Kerpicci, Kemal Sarioglu, Numerical Investigation of Oil Flow in a Hermetic Compressor, International journal of materials, Volume 7, 2020, pp. 25-28.

[43] A Alblooshi, M Alavi, SS Dol, "A Regression Analysis of Factors Affecting Global Crude Oil and Gas Price", INTERNATIONAL HAZAR SCIENTIFIC RESEARCHES CONFERENCE, Baku Azerbaijan, 2021.

\section{Contribution of Individual Authors to the Creation of a Scientific Article (Ghostwriting Policy)}

- Niraj Baxi and Dr. Sharul Sham Dol carried out Conceptualization, writing original draft, Reviewing and editing and Formal analysis.

- Dr. Sharul Sham Dol and Dr. Mior Azman Meor Said carried out project supervision, methodology and project administration.

\section{Creative Commons Attribution License 4.0 (Attribution 4.0 International, CC BY 4.0)}

This article is published under the terms of the Creative Commons Attribution License 4.0 https://creativecommons.org/licenses/by/4.0/deed.en US 